\title{
THREE-PHASE TO SINGLE-PHASE GENERATION SYSTEM BASED ON DOUBLY-FED INDUCTION GENERATOR
}

\author{
Filipe V. Rocha ${ }^{1}$, Nady Rocha ${ }^{1}$, Victor F. M. B. Melo ${ }^{1}$, Edison R. C. da Silva ${ }^{1}$, Cursino B. Jacobina ${ }^{2}$ \\ ${ }^{1}$ Federal University of Paraíba, João Pessoa - Paraíba, Brazil \\ ${ }^{2}$ Electrical Engineering Department - Federal University of Campina Grande - UFCG - Campina Grande, Paraíba, Brazil \\ e-mail: filipe.rocha@cear.ufpb.br, nadyrocha@cear.ufpb.br, victor@cear.ufpb.br, edison.roberto@cear.ufpb.br, \\ jacobina@dee.ufcg.edu.br
}

\begin{abstract}
This paper presents a three-phase to singlephase six-leg converter for a wind energy conversion system based on Doubly-Fed Induction Generator (DFIG). The converter is composed of six legs and is divided in three parts: the grid-side converter (GSC), which is responsible for power factor and DC-link voltage controls, the stator-side converter (SSC), which guarantees the control of the stator voltage, and the rotor-side converter (RSC), which is responsible for vector control of the generator. One of the converter's legs is shared by gridside and stator-side converters. The main advantages of the proposed configuration compared to other topologies presented in the literature are providing balanced threephase voltages to the DFIG, simple control system and not having any limitation with respect to synchronization between grid and stator voltages and DC-link voltage. The system model, pulse-width modulation (PWM) and control strategies are discussed and simulation and experimental results are presented in order to prove the feasibility of the system.
\end{abstract}

Keywords - DFIG, THREE-PHASE TO SINGLEPHASE, WECS.

\section{INTRODUCTION}

Energy demand has increased significantly in the last decades and, to ensure the energy security, renewable sources have been increasingly explored [1]-[4]. Wind energy is one of the most competitive among renewable energies. Low cost generation systems are based on wind turbines with fixed speed, usually using squirrel cage induction generator (SCIG). The generator is connected to the grid (single-phase or threephase source) and the reactive power and grid voltage cannot be controlled [5], [6]. In variable speed systems, the generator is connected to the grid through an AC-DC-AC converter. Employing either SCIG or permanent magnet synchronous generator (PMSG), the generator is connected to a full power AC-DC-AC converter, meaning that all of the generator power is processed by the converter [7]-[13].

When only single-phase grid is available (common condition in rural or remote areas), the connection between a three-phase generator and the single-phase grid can be obtained from a three-phase to single-phase converter. In [5] a three-phase SCIG was connected to a single-phase grid

This footnote will be used only by the Editor and Associate Editors. The edition in this area is not permitted to the authors. This footnote must not be removed while editing the manuscript. by means of a five-leg converter, in which the generator side converter was composed of three legs and the grid side converter was composed of two legs, all sharing the same DClink. In [14], a low-cost system was proposed to connect a three-phase SCIG to a single-phase grid. The generator's phases were delta-connected and a capacitor was parallelconnected to one of the phases, using the Steimetz connection. In [11], a three-phase SCIG is connected to a single-phase grid using parallel converters in order to reduce the current per leg in the grid, reducing, in turn, semiconductor losses and switches current rating.

On the other hand, very few single-phase to three-phase wind energy systems based on doubly-fed induction generator (DFIG) were discussed in the literature [15]-[17]. A structure of a single-phase grid connected to a three-phase DFIG was discussed in [15], which is illustrated in Figure 1.a. An inverter is connected to the three-phase rotor of the DFIG, while the three-phase stator is connected to a single-phase grid. Needless to say, the DFIG stator operates under unbalanced condition, which brings high complexity to the control system in order to adjust speed, stator reactive power and grid power factor. Besides, the inverter uses a floating capacitor, since the system operates employing the single external feeding (SEF) concept, which complicates even more the control system.

Other possible structure was proposed in [16], in which a DFIG is composed of a three-phase rotor, fed by an inverter, and a single-phase stator, which is connected directly to the grid. This configuration avoids the unbalanced operation observed in the topology of Figure 1.a, but single-phase DFIG with three-phase rotor is not easily found in trade.At last, in [17] the authors proposed three single-phase to threephase converter topologies for DFIG composed of eight, seven and six legs. Pulse-Width Modulation (PWM) and control strategies were presented and a semiconductor losses analysis was performed. According to this analysis, the best performance was achieved with the seven-leg topology illustrated in Figure 1.b. Note that there is a shared leg between the DFIG stator and the grid. This requires synchronization between the grid voltage and stator voltage, otherwise the level of DC-link voltage and the power processed by the converter may increase. However, the six-leg topology is not interesting at all, because the dc-link voltage is bigger than the seven-leg topology. It has to use the double of dc-link voltage.

This paper proposes a single-phase to three-phase topology in which the DFIG is directly connected to the single-phase grid and the converter processes only part of the overall output power. The converter is divided into three parts as shown in 


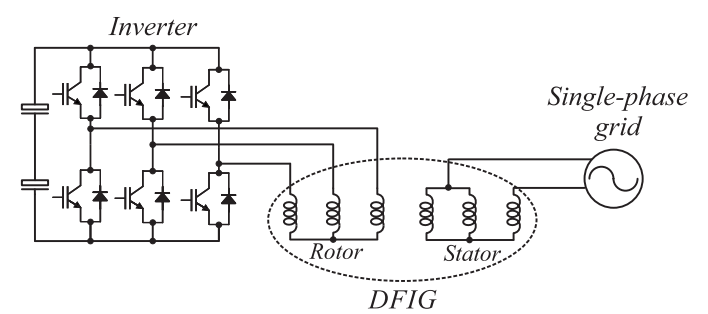

(a)

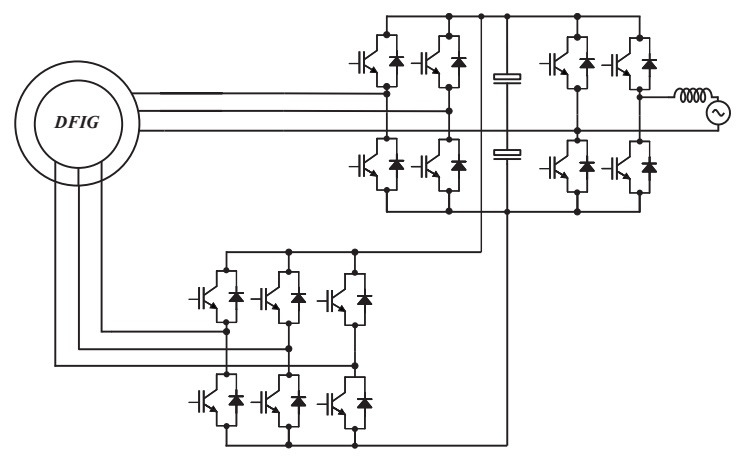

(b)

Fig. 1. Topologies discussed in (a) [15]. (b) [17].

Figure 2. The grid-side converter (GSC), which is responsible for power factor and DC-link voltage controls, the stator-side converter (SSC), which guarantees stator voltage control, and the rotor-side converter (RSC), which is responsible for vector control of the DFIG. Compared to other topologies presented in the literature, the proposed system has the advantages of providing balanced three-phase voltages to the DFIG, simple control system and does not have any limitation with respect to synchronization between grid and stator voltages and DClink voltage. The structures illustrated in Figure 1 will be considered as conventional topologies for benchmarking purposes. The proposed system was previously analyzed in [18], but this paper adds information regarding the controllers design and new experimental results of the proposed rotor control system.

\section{MACHINE MODEL}

The induction generator model in $d-q$ generic reference frame is given by [19]:

$$
\begin{aligned}
\bar{v}_{s}^{g} & =r_{s} \bar{i}_{s}^{g}+\frac{d}{d t} \bar{\phi}_{s}^{g}+j \omega_{g} \bar{\phi}_{s}^{g} \\
\bar{v}_{r}^{g} & =r_{r} \bar{i}_{r}^{g}+\frac{d}{d t} \bar{\phi}_{r}^{g}+j\left(\omega_{g}-\omega_{r}\right) \bar{\phi}_{r}^{g} \\
\bar{\phi}_{s}^{g} & =\left(l_{l s}+l_{m}\right) \bar{i}_{s}^{g}+l_{m} \bar{i}_{r}^{g} \\
\bar{\phi}_{r}^{g} & =l_{m} \bar{i}_{s}^{g}+\left(l_{l r}+l_{m}\right) \bar{i}_{r}^{g} \\
c_{e} & =2 P l_{m} \mathfrak{I}\left(\bar{i}_{s}^{g} \bar{i}_{r}^{g *}\right) \\
P_{s} & =\left(v_{s d}^{g} i_{s d}^{g}+v_{s q}^{g} i_{s q}^{g}\right) \\
Q_{s} & =\left(v_{s d}^{g} i_{s q}^{g}-v_{s q}^{g} i_{s d}^{g}\right)
\end{aligned}
$$

where $j=\sqrt{-1}$ is an imaginary number, $\bar{x}_{n}^{g}=x_{n d}^{g}+j x_{n q}^{g}$ is the vector of variable $x$ in generic reference with $n=s, r(s=$ stator and $r=$ rotor), $x=v, i, \phi$, and $\mathfrak{I}(z)$ is the imaginary part of $z$. Furthermore, $\bar{v}, \bar{i}$ and $\bar{\phi}$ are vectors of voltage, current and flux, respectively; $\omega_{g}$ is the rotation speed generic reference frame and $\omega_{r}$ is the electrical rotor speed; $r_{s}$ and $r_{r}$ are the resistance of the stator and rotor, respectively; $l_{l s}$ and $l_{l r}$ are the leakage inductances of stator and rotor, respectively; $l_{m}$ is the stator-rotor mutual inductance; $c_{e}$ is the electrical torque; $P$ pair of poles; $P_{S}$ and $Q_{s}$ are the stator active and reactive powers, respectively.

\section{SYSTEM MODEL}

The proposed configuration illustrated in Figure 2 consists in three parts: grid-side, stator-side and the rotor-side converters (GSC, SSC and RSC, respectively). These converters depict a single-phase AC-DC-AC converter with a share leg (leg $s$ ). The mathematical model of the system is given by:

$$
\begin{aligned}
e_{g} & =r_{a} i_{1}+l_{a} \frac{d i_{1}}{d t}+r_{a} i_{2}+l_{a} \frac{d i_{2}}{d t}+v_{g} \\
v_{s 32} & =r_{a} i_{3}+l_{a} \frac{d i_{3}}{d t}+r_{a} i_{2}+l_{a} \frac{d i_{2}}{d t}+v_{32} \\
i_{1} & =-i_{s 1}+i_{g} \\
i_{2} & =i_{s 2}+i_{g} \\
i_{3} & =-i_{s 3} \\
v_{g} & =v_{g 10}-v_{s 0} \\
v_{32} & =v_{s 10}-v_{s 0},
\end{aligned}
$$

where $r_{a}$ and $l_{a}$ represent the resistance and inductance of inductor filter, respectively, $v_{g}$ and $v_{32}$ are the voltages of the GSC and SSC, respectively, $v_{g 10}$ and $v_{s 10}$ are the pole voltages of the GSC and SSC, respectively, $v_{s 0}$ is the pole voltage of the shared-leg between the GSC and SSC, $i_{g}$ is the grid current, $i_{1}$, $i_{2}$ and $i_{3}$ are the currents of GSC and SSC and $i_{s 1}, i_{s 2}$ and $i_{s 3}$ are the generator currents. From (8) the voltage of the gridside converter $\left(v_{g}=v_{g 10}-v_{s 0}\right)$ can be used to regulate the grid current and from (9) the voltage of the SSC $\left(v_{32}=v_{s 10}-v_{s 0}\right)$ can be used to control the line machine voltage $v_{s 23}$ since the line voltage $v_{s 12}$ is already defined by the grid voltage. The model of the RSC is similar to that of the conventional threephase system [19].

\section{CONTROL STRATEGY}

Figure 3 shows the control block diagram of the proposed system. The control block is divided in the DC-link voltage and power factor control (realized by means of the GSC), the line voltage control (realized by means of the SSC) and the active and reactive power control (realized by means of the RSC). The grid-side converter control consists of two cascaded control loops. In the outer loop, the capacitor DClink voltage $v_{C}$ is adjusted to its reference value $v_{C}^{*}$ utilizing a PI type controller, represented by block $R_{C}$. The output of the DC-link voltage control is the amplitude of the reference current of the single-phase grid $\left(I_{g}^{*}\right)$. The instantaneous reference current $\left(i_{g}^{*}\right)$ is synchronized with the grid voltage by means of a Phase Locked Loop (PLL) scheme [20] represented in Figure 3 by block $G_{i r}$. In the inner current loop, the grid current control is implemented using a resonant controller described in [21]. This controller is represented by block $R_{g}$. The output of the current control defines the reference voltage $v_{g}^{*}$. 


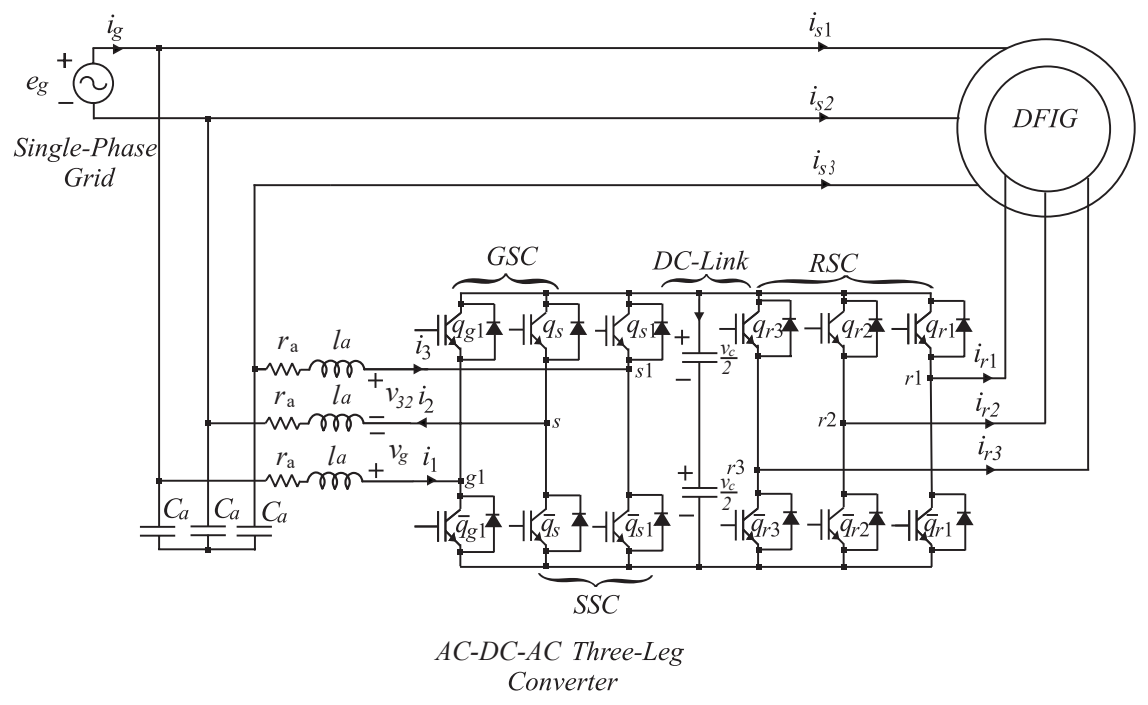

Fig. 2. Proposed topology.

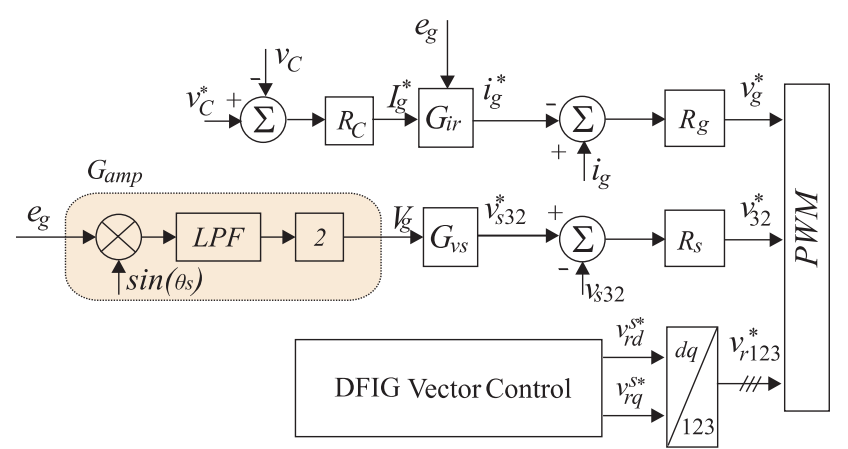

Fig. 3. Control block diagram converters GSC and SSC.

At the stator-side converter, the line voltage control is realized also using a resonant controller, represented by block $R_{s}$. As the voltage $v_{s 12}$ is already defined by the grid voltage, because the grid source is directly connected to the generator, the amplitude of grid voltage is estimated by block $G_{a m p}$ to ensure the balanced three-phase voltages. As presented in Figure 3, the $G_{a m p}$ block extracts the amplitude of the $e_{g}$ (i.e., $V_{g}$ ) multiplying the grid voltage $e_{g}$ by an unity sinusoidal signal. The angle of the sinusoidal signal is obtained using a PLL scheme and it is approximately equal to the angle of the grid voltage. Thus, with a Low Pass Filter (block $L P F$ ), the amplitude of the grid voltage is extracted $\left(V_{g}\right)$. Then, the reference line voltage $v_{s 32}^{*}$ is determined by the block $G_{v s}$ and it is compared to the measured line voltage $v_{s 32}$. Thereafter, the controller $\left(R_{s}\right)$ determines the reference voltage $v_{32}^{*}$.

\section{A. DFIG Vector Control}

There are two main DFIG control strategies: the Direct Power Control (DPC), where the reference voltages are obtained from the direct control of active and reactive power [22]; and Voltage Oriented Control (VOC), where the reference voltages are obtained from the cascade control of the active and reactive power with the $d q$ components of the rotor current in the stator voltage reference [23].

The VOC was the strategy used in this work. Block diagram of the control RSC is shown in Figure 4. The reference $d$-axis is chosen to align with the stator voltage, resulting in null value for the stator voltage component $q$-axis $\left(v_{s q}^{v}=0\right)$. Thus, from (3), (6) and (7) it is possible to write the equations of active and reactive power of the stator as functions of the rotor currents as:

$$
\begin{gathered}
P_{s}=-\frac{l_{m} v_{s d}^{v}}{l_{s}} i_{r d}^{v} \\
Q_{s}=\frac{l_{m} v_{s d}^{v}}{l_{s}} i_{r q}^{v} .
\end{gathered}
$$

In (15) and (16) it is noted that the active and reactive power are decoupled in terms of the $d q$ currents of rotor. In this way, the method of control is based on decoupled control of active and reactive power. The reference $d q$ rotor currents are obtained using two PI controllers, where the active power loop defines the $i_{r d}^{v *}$ component and the reactive power loop determines the $i_{r q}^{\nu *}$ component. The current control is realized in the stationary reference frame. Then, the currents $i_{r d}^{s *}$ and $i_{r q}^{s *}$ are obtained from coordinate transform $e^{j \theta}$, where $\theta$ is the angle between the stator voltage reference frame and the stator reference frame. They are compoared to the measured values and controlled by resonant PI controllers (PI-R), obtaining the rotor voltages in the stator reference frame. From the rotor position and coordinate transform $e^{-j \varepsilon}$, where $\varepsilon$ is the angle between the stator reference frame and the rotor reference frame. The rotor reference voltages are determined in the rotor reference frame, and then the voltages $v_{r 1}^{*}, v_{r 2}^{*}$ and $v_{r 3}^{*}$ are obtained from $d q-123$ block, based on Park's transform. The rotor voltages are used in the PWM strategy.

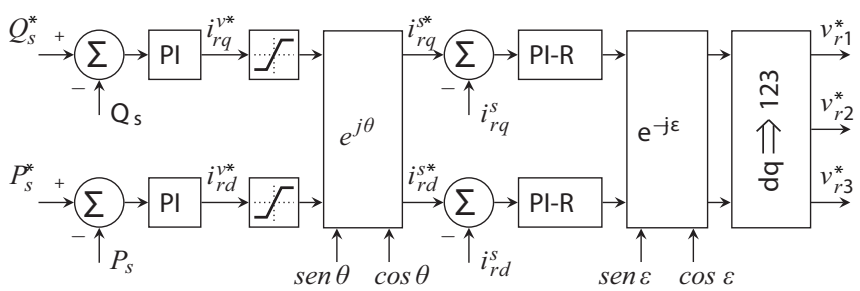

Fig. 4. Block diagram of power system. 

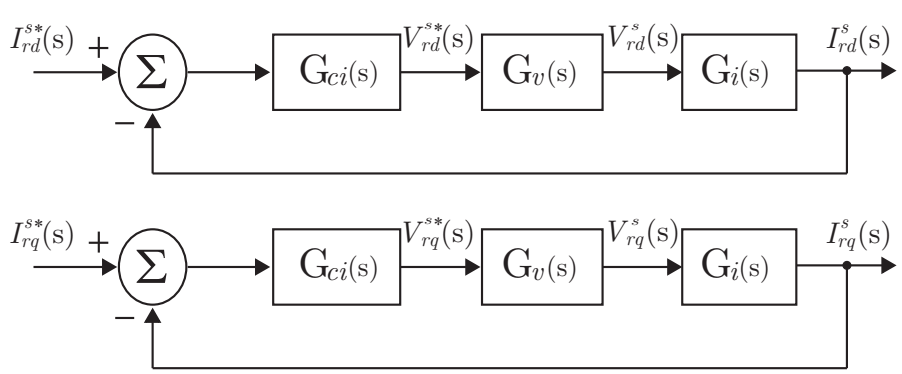

Fig. 5. Block diagram of current control system.

1) Design of Current Controllers: From the equations of the dynamic modeling of the DFIG, a current control loop is defined, as illustrated in Figure 5. $G_{i}(s)$ is the transfer function of the current plant, $G_{v}(s)$ is the voltage source represented by a first order transfer function with time constant $T_{v}$ and $G_{c i}(s)$ the transfer function of the PI controller.

$$
\begin{array}{r}
G_{i}(s)=\frac{I_{r d}^{s}(s)}{V_{r d}^{s}(s)}=\frac{I_{r q}^{s}(s)}{V_{r q}^{s}(s)}=\frac{\frac{1}{r_{s r}}}{\frac{\sigma l_{r}}{r_{s r}} s+1} \\
G_{v}(s)=\frac{V_{r d}^{s *}(s)}{V_{r d}^{s}(s)}=\frac{V_{r q}^{s *}(s)}{V_{r q}^{s}(s)}=\frac{1}{T_{v} s+1} \\
G_{c i}=\frac{K_{i i}}{s}\left(\frac{K_{p i}}{K_{i i}} s+1\right) \\
\sigma=1-\frac{l_{m}^{2}}{l_{s} l_{r}} \\
r_{s r}=\frac{\left(l_{s}-\sigma l_{s}\right) r_{r}}{l_{r}}
\end{array}
$$

where $\sigma$ is leakage coefficient, $l_{s}\left(l_{s}=l_{l s}+l_{m}\right)$ and $l_{r}\left(l_{r}=\right.$ $\left.l_{l r}+l_{m}\right)$ are the inductances of stator and rotor, respectively. The closed loop transfer function shown in (22) is obtained by canceling the current plant pole $\left(s=-\frac{r_{s r}}{\sigma l_{r}}\right)$ with the zero of the PI controller $\left(s=-\frac{K_{i i}}{K_{p i}}\right)$. The gains $K_{i i}$ and $K_{p i}$ are calculated in order to obtain real and identical poles of the closed-loop transfer function $G_{f I}$.

$$
\begin{aligned}
G_{f I}(s) & =\frac{K_{i i} / r_{s r}}{T_{v} s^{2}+s+\left(K_{i i} / r_{s r}\right)} \\
K_{i i} & =\frac{r_{s r}}{4 T_{v}} \\
K_{p i} & =\frac{\sigma l_{r}}{4 T_{v}} .
\end{aligned}
$$

2) Design of Power Controllers: The power control loop is shown in Figure 6, in which $G_{c p}(s)$ and $G_{c q}(s)$ are the transfer functions of the active and reactive PI controllers, respectively; $G_{p}(s)$ and $G_{q}(s)$ are the transfer functions obtained from (15) and (16) and $G_{f I}(s)$ is the internal loop of the current control, which is approximated to a first-order function.

$$
\begin{gathered}
G_{p}(s)=G_{q}(s)=\frac{P_{s}(s)}{I_{r q}^{s}(s)}=\frac{Q_{s}(s)}{I_{r d}^{s}(s)}=\frac{l_{m} V_{s}}{l_{s}} \\
G_{c p}=G_{c q}=\frac{K_{i p q}}{s}\left(\frac{K_{p p q}}{K_{i p q}} s+1\right) \\
G_{f I}=\frac{1}{\left(2 T_{v} s+1\right)^{2}} \approx \frac{1}{4 T_{v} s+1}
\end{gathered}
$$

From (25)-(27) closed-loop transfer function is defined by:

$$
G_{f p}(s)=G_{f q}(s)=\frac{\frac{l_{m} V_{s} K_{p p q} s+l_{m} V_{s} K_{i p q}}{4 l_{s} T_{v}}}{s^{2}+\frac{l_{m} V_{s} K_{p p q}+l_{s}}{4 l_{s} T_{v}} s+\frac{l_{m} V_{s} K_{i p q}}{4 l_{s} T_{v}}} .
$$

The denominator can be represented by polynomial characteristic of a second-order system $s^{2}+2 \xi \omega_{n} s+\omega_{n}^{2}$, where $\omega_{n}$ is natural frequency and $\xi$ is damping factor. Then the gain is given by:

$$
\begin{aligned}
K_{i p q}(s) & =\frac{4 l_{s} T_{v} \omega_{n}^{2}}{l_{m} V_{s}} \\
K_{p p q}(s) & =\frac{1}{l_{m} V_{s}}\left(8 l_{s} T_{\nu} \xi \omega_{n}-l_{s}\right)
\end{aligned}
$$

where the values of the damping factor, natural frequency and $T_{v}$ are $\xi=0.8, \omega_{n}=9.5 \mathrm{rad} / \mathrm{s}$ and $T_{v}=0.01 \mathrm{~s}$, respectively.

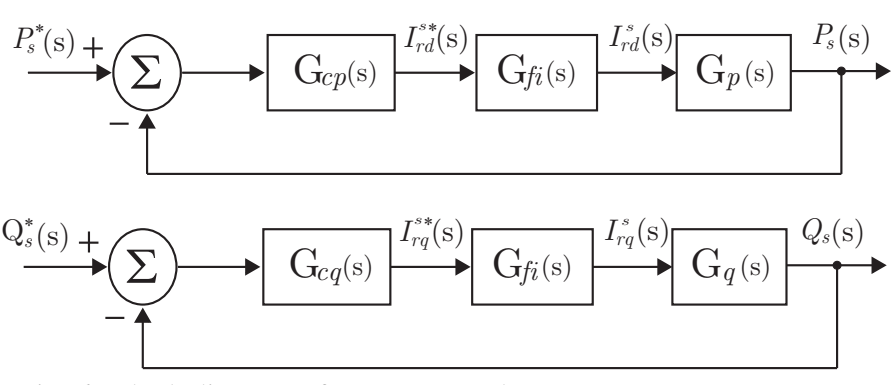

Fig. 6. Block diagram of power control system.

\section{PWM STRATEGY}

The RSC can be commanded by using an adequate PWM strategy for three-phase voltage source inverter [24]-[26]. Only the PWM implementation of grid and stator side converters is highlighted in this paper.

In Sinusoidal PWM (SPWM) the reference pole voltages are compared with a high frequency triangular signal to determine the switch states. Considering that $v_{g}^{*}$ is the GSC reference voltage and $v_{32}^{*}$ is the SSC reference voltage, they can be defined based on the reference pole voltages by

$$
\begin{aligned}
v_{g}^{*} & =v_{g 10}^{*}-v_{s 0}^{*} \\
v_{32}^{*} & =v_{s 10}^{*}-v_{s 0}^{*} .
\end{aligned}
$$

In order to determine the three pole voltages, an auxiliary variable $v_{x}^{*}$ must be added. By making $v_{x}^{*}=v_{s 0}^{*}$, the reference pole voltages $v_{g 10}^{*}, v_{s 0}^{*}$ and $v_{s 10}^{*}$ are determined by:

$$
\begin{aligned}
v_{g 10}^{*} & =v_{g}^{*}+v_{x}^{*} \\
v_{s 0}^{*} & =v_{x}^{*} \\
v_{s 10}^{*} & =v_{32}^{*}+v_{x}^{*} .
\end{aligned}
$$

The choice of the auxiliary variable $v_{x}^{*}$ is free in a range defined by the limits of the pole voltages $\pm v_{C}^{*} / 2$.

The voltage $v_{x}^{*}$ must be chosen such that:

$$
\begin{aligned}
& v_{x \min }^{*} \leq v_{x}^{*} \leq v_{x \max }^{*} \\
& v_{x \min }^{*}=-\frac{v_{C}^{*}}{2}-\min \left\{v_{g}^{*}, v_{32}^{*}, 0\right\} \\
& v_{x \max }^{*}=\frac{v_{C}^{*}}{2}-\max \left\{v_{g}^{*}, v_{32}^{*}, 0\right\},
\end{aligned}
$$


where $v_{C}^{*}$ is the reference DC-link voltage. Once $v_{x}^{*}$ is determined, the reference pole voltages $v_{g 10}^{*}, v_{s 0}^{*}$ and $v_{s 10}^{*}$ are obtained from (33) to (35).

\section{ANALYSIS OF GSC AND SSC}

\section{A. Normalized Currents Processed by GSC and SSC}

The currents of the GSC and SSC are defined as $i_{1}, i_{2}$ and $i_{3}$ and are determined by (10)-(12). Figure 7 shows currents RMS values normalized by nominal generator current $\left(i_{s n}\right)$. The curves shown in Figure 7 were obtained considering four different mechanical torques $[100 \%, 75 \%, 50 \%$ and $25 \%$ of the nominal (rated) mechanical torque] with the range of the rotor speed being from 0.7 to 1.3 of the synchronous speed.

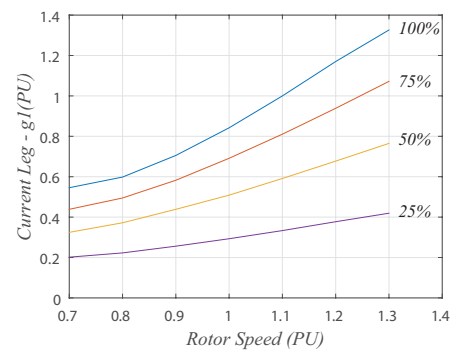

(a)

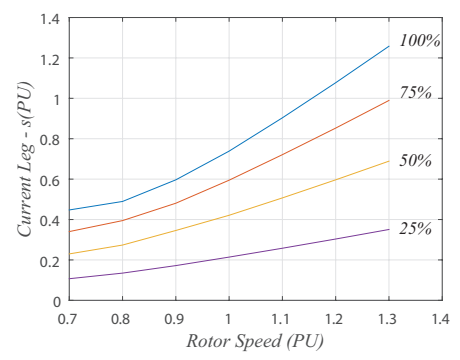

(b)

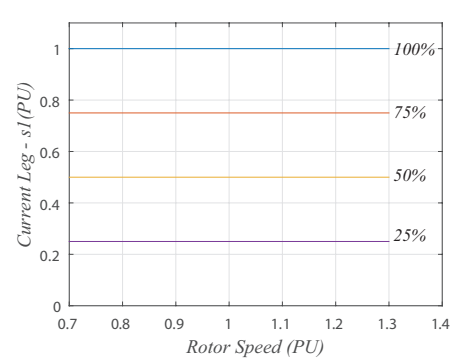

(c)

Fig. 7. Normalized currents. (a) Current of the leg $g 1$. (b) Current of the leg $s$. (c) Current of the leg $s 1$.

Figures 7.a and 7.b show that currents of the GSC (legs $g 1$ and $s$, respectively) depend on the rotor speed of the DFIG. In subsynchronous operation, the rotor absorbs power from the grid. Because of this, the currents $i_{1}$ and $i_{2}$ present lower values than those observed in the case of supersynchronous operation. In addition, in supersynchronous operation, these currents are greater than the stator current of the leg $s 1$, shown in Figure 7.c. As can be seen, currents $i_{1}$ and $i_{2}$ can be up to $30 \%$ higher than the currents of the generator. From this analysis, it is noted that the higher effort in the switch occurs in supersynchronous operation with rotor speed of $1.3 \mathrm{pu}$, in which the device must handle 1.3 of the nominal current of the DFIG.

\section{B. Normalized Apparent and Active Power Processed by GSC and SSC}

The apparent powers of the GSC and SSC are defined as $S_{g s c}$ and $S_{s s c}$, respectively. In this analysis, the stator reactive power is null, then the stator active power is equal to apparent power $\left(S_{s}=P_{s}\right)$. The nominal (rated) apparent power of the machine is defined as $S_{s n}$. Figure 8 shows the normalized apparent power curves $\left|S_{g s c} / S_{s n}\right|$ and $\left|S_{s s c} / S_{s n}\right|$. The apparent powers $S_{g s c}, S_{s s c}$, are defined by:

$$
\begin{aligned}
S_{g s c} & =\frac{1}{2} \bar{v}_{g} \bar{i}_{1}^{*} \\
S_{s s c} & =\frac{1}{2} \bar{v}_{32} \bar{i}_{3}^{*}
\end{aligned}
$$

where $\bar{i}_{1}^{*}$ and $\bar{i}_{3}^{*}$ are the complex conjugate of the vector currents $\bar{i}_{1}$ and $\bar{i}_{3}$, respectively. These results were obtained considering four different values for the mechanical torque $[100 \%, 75 \%, 50 \%$ and $25 \%$ of the nominal (rated) mechanical torque] with the range of the rotor speed being from 0.7 to 1.3 of the synchronous speed. From Figure 8.a, it is possible to see that the normalized apparent power processed by the SSC represents only a fraction of the apparent generator power. For example, when rated torque is applied, the power handled by the SSC is approximately $60 \%$ of the DFIG's rated power.

On the other hand, with respect to the power of the GSC, as can be seen in Figure 8.b, it depends on the rotor speed and therefore on the rotor power flow. In subsynchronous operation, the power is delivered to the rotor by the RSC. Therefore, part of the power delivered by the stator is transferred to the rotor by means of SSC and RSC, while GSC delivers just a small part of power to the grid. For example, with rated torque and rotor speed of $0.7 \mathrm{pu}$, the power processed by the GSC is approximately of $30 \%$ of the rated power (see Figure 8.b).

Now considering supersynchronous operation, the rotor must deliver power. Therefore, all power processed by SSC and RSC is delivered to the grid by means of the GSC. Therefore, power processed by GSC increases. For example, with rated torque and rotor speed of $1.3 \mathrm{pu}$, the power processed by the GSC is approximately of $80 \%$ of the rated power (see Figure 8.b). It is worth to point out that in all cases neither the SSC nor the GSC process the total power of the generator. It represents an advantage when compared to full-rated systems, like the one illustrated in Figure 1.b. From this analysis, it is possible to see that, in the worst case (supersynchronous operation with rotor speed of $1.3 \mathrm{pu}$ ), the SSC and GSC converters processed power of approximately $60 \%$ and $80 \%$ of nominal, respectively. This implies the use of lower rated and cheaper devices.

For power flow analysis of SSC and GSC converters an active power study was performed in Figure 9. Figure 9.a shows the active power in the SSC. It is observed that at all operating points the power is negative. This shows that the active power flows from DFIG stator to SSC at all points. Note that the highest power processing happens at the 1.3 $\mathrm{pu}$ rotor speed. This is because the generator works in 


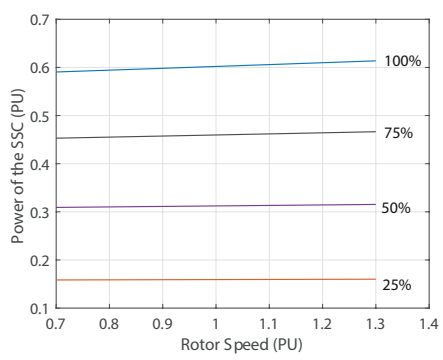

(a)

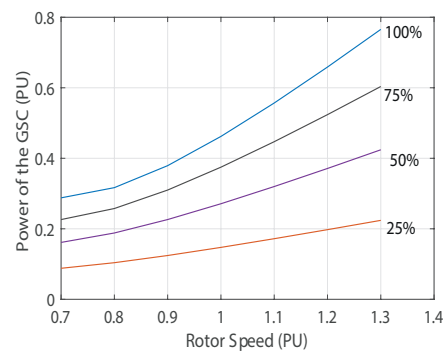

(b)

Fig. 8. Normalized Power. (a) Apparent power of SSC. (b) Apparent power of the GSC.

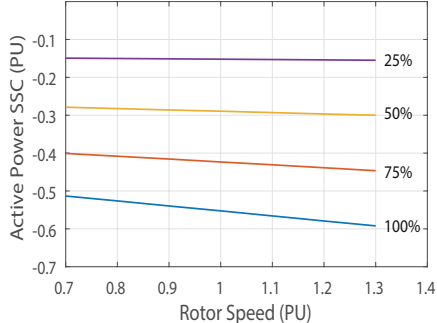

(a)

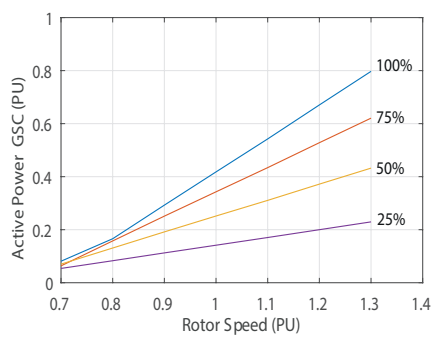

(b)

Fig. 9. Normalized Power. (a) Active power of SSC. (b) Active power of GSC.

supersynchronous mode, so the rotor provides power to the RSC and increases the energy processed by the SSC. Figure 9.b shows the active power in the GSC. Unlike the SSC converter, the GSC has positive active power at all operating points, which means that the power flows from GSC to the grid. For subsynchronous mode the power processed by the GSC is low because the rotor absorbs a portion of the SSC power flow, while for supersynchronous mode the rotor provides power, so the GSC processes the rotor power flow plus the SSC power flow.

\section{DC-LINK CAPACITOR}

The methodology employed for the capacitors design can be found in [27]. By means of harmonic spectrum analysis of the DC-link current, the presence of dominant high or low frequency components are determined. In single-phase to three-phase systems the predominant component in the capacitor current is twice the grid frequency, so according to [27], the capacitance can be determined by:

$$
C=\frac{P_{\text {load }}}{240 V_{s} f_{\text {grid }} V_{\text {ripple }}}
$$

where $C$ is the capacitance of DC-link voltage, $P_{\text {load }}$ power of DFIG, $f_{\text {grid }}$ is the grid frequency, $V_{s}$ is the stator voltage in RMS value and $V_{\text {ripple }}$ is the ripple voltage of DC-link. For the system parameters with a capacitance of $2200 \mu \mathrm{F}$ a ripple of less than $1 \%$ was obtained.

\section{SIMULATION RESULTS}

In order to demonstrate the validity of the model and PWM and control strategies for the proposed topology, digital simulations have been performed. Current and power control gains are $K_{i i}=350.5, K_{p i}=1.44, K_{i p q}=0.07$ and $K_{p p q}=$ 0.002 . DFIG parameters used in simulation are shown in Table I, while the setup parameters are shown in Table II.

Figures 10 and 11 illustrate the steady-state curves obtained for the proposed topology. Stator active and reactive power references were $-500 \mathrm{~W}$ and $0 \mathrm{VA}$, respectively. The system is working in supersynchronous mode with a speed of $477 \mathrm{rad} / \mathrm{s}$. Power waveforms are illustrated in Figure 10.a, which shows that both active and reactive powers assume their reference values. And using Park's transformation with stator voltage reference frame [23], the obtained rotor current components $i_{r d}^{v}$ and $i_{r q}^{v}$ are illustrated in Figure 10.b. From Figures 10.a and $10 . \mathrm{b}$, it is possible to see that RSC control operated adequately. Also, as shown in Figures 10.c and 10.d, stator line voltages provided by PWM and control strategies are sinusoidal and balanced, producing balanced currents, which is an advantage when compared to topology of Figure 1.a.

On the other hand, PWM and control strategies operated adequately providing sinusoidal grid current with high power factor, as illustrated in Figure 11.a. The phase opposition between the grid voltage and grid current shows that the single-phase grid was receiving power of GSC. Also, DClink voltage is well adjusted to its reference value, as seen in Figures 11.b and 11.c illustrates the converter currents, it is observed that current $i_{3}$ is equal to $-i_{s 3}$ and $i_{1}$ and $i_{2}$ are a linear combination of $i_{g}, i_{s 1}$ and $i_{s 2}$.

Figure 12 shows the transient performance of the system, when the reference of the stator power was changed from -250 $\mathrm{W}$ to $-500 \mathrm{~W}$ at the time of $4.5 \mathrm{~s}$. The reactive power reference was kept null and DC-link voltage reference was maintained $400 \mathrm{~V}$ [see Figure 12.a and 12.b]. With the increase of the power provided by the generator, the grid current increased as shown in Figure 12.d. 


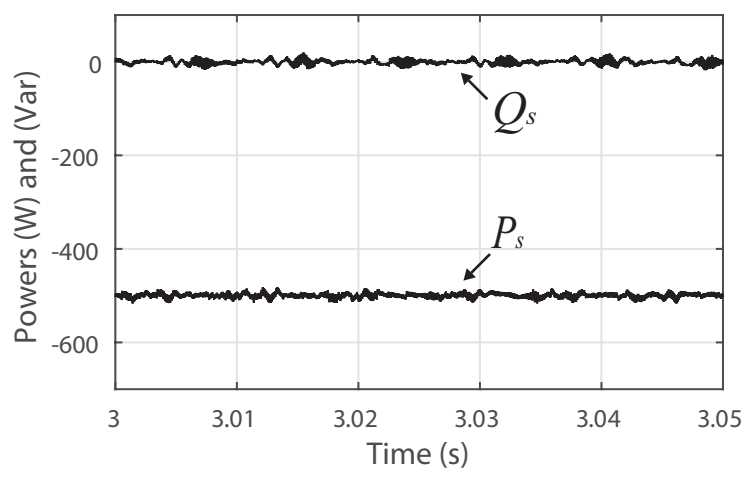

(a)

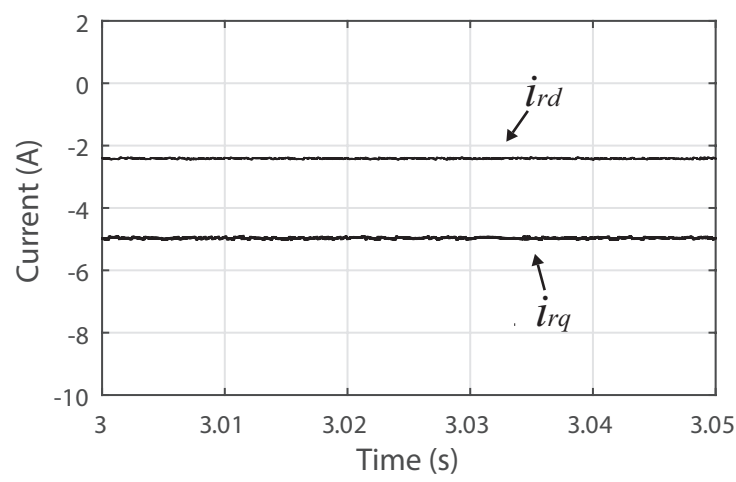

(b)

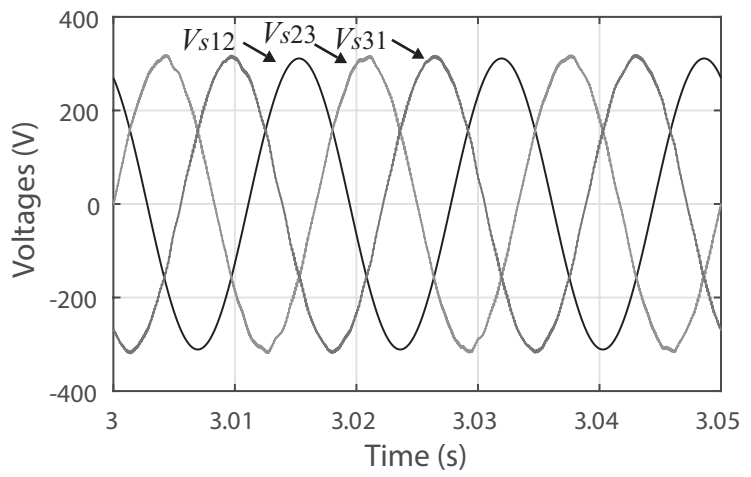

(c)

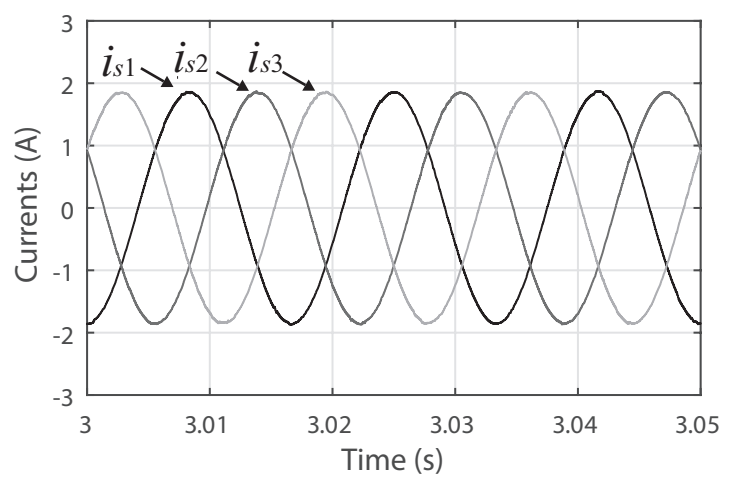

(d)

Fig. 10. Simulation results - steady-state. (a) Stator active and reactive power $\left(P s, Q_{s}\right)$. (b) $d-q$ rotor currents $\left(i_{r d}^{v}\right.$ and $\left.i_{r q}^{v}\right)$. (c) Stator line voltages $\left(v_{s 12}, v_{s 23}\right.$ and $\left.v_{s 31}\right)$. (d) Stator currents $\left(i_{s 1}, i_{s 2}\right.$ and $i_{s 3}$ ).

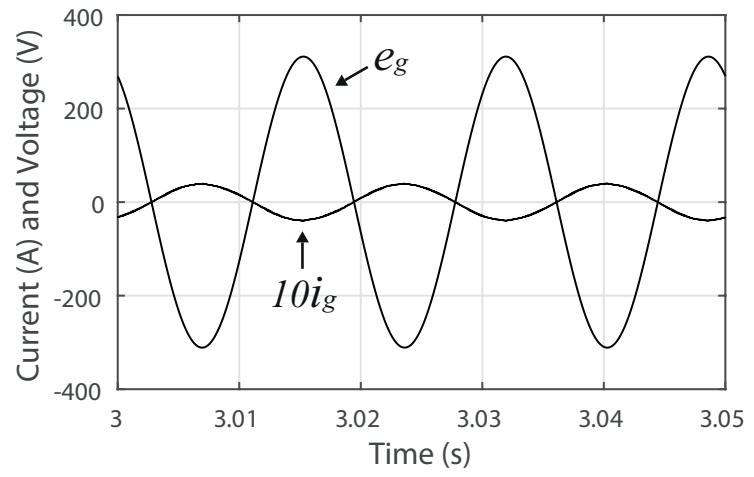

(a)

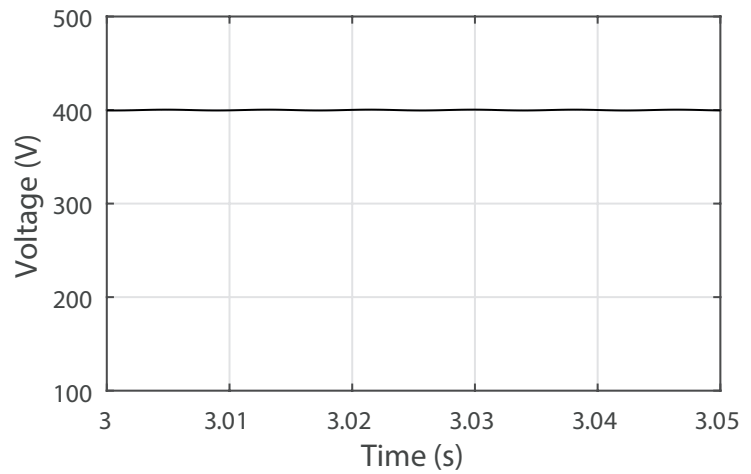

(b)

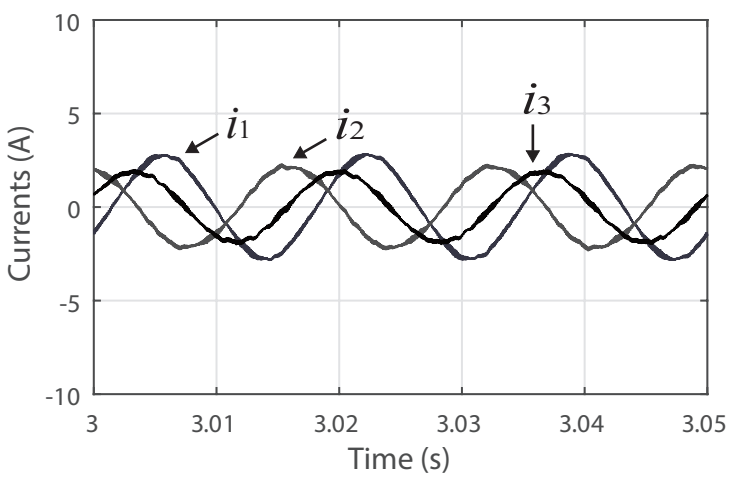

(c)

Fig. 11. Simulation results - steady-state. (a) Current and voltage of the grid $\left(i_{g}\right.$ and $e_{g}$ ). (b) DC-link voltage $\left(v_{C}\right)$. (c) SSC and GSC currents $\left(i_{1}, i_{2}\right.$ and $\left.i_{3}\right)$.

TABLE I

\section{DFIG Parameters}

\begin{tabular}{cc}
\hline Parameter & Value \\
\hline$r_{s}$ & $15.1 \Omega$ \\
\hline$l_{l s}$ & $39.9 \mathrm{mH}$ \\
\hline$r_{r}$ & $6.22 \Omega$ \\
\hline$l_{l r}$ & $19.9 \mathrm{mH}$ \\
\hline$l_{m}$ & $0.5238 \mathrm{H}$ \\
\hline$P$ & 1 \\
\hline Rated line voltage & $220 \mathrm{Vrms}$ \\
\hline Rated power & $0.55 \mathrm{~kW}$ \\
\hline Frequency & $60 \mathrm{~Hz}$
\end{tabular}




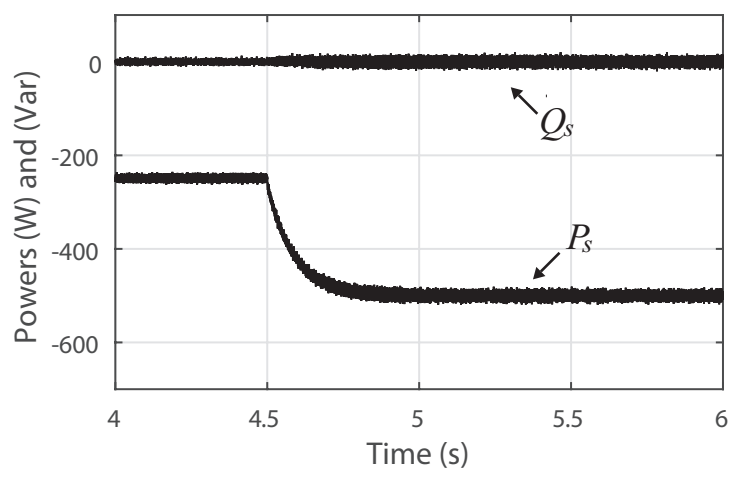

(a)

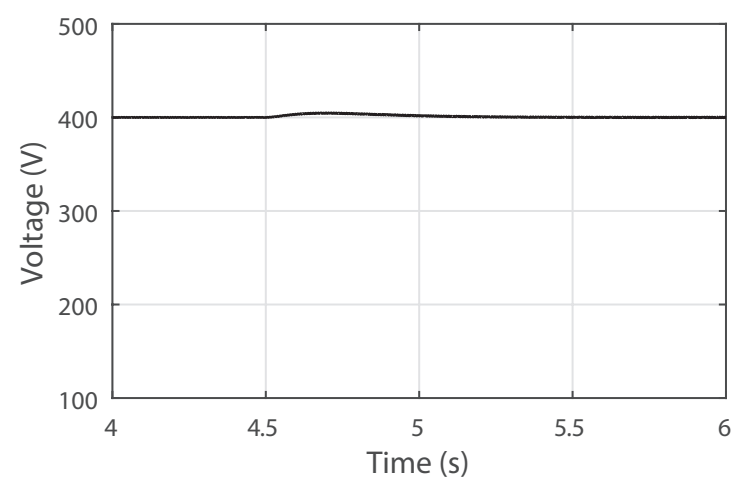

(b)

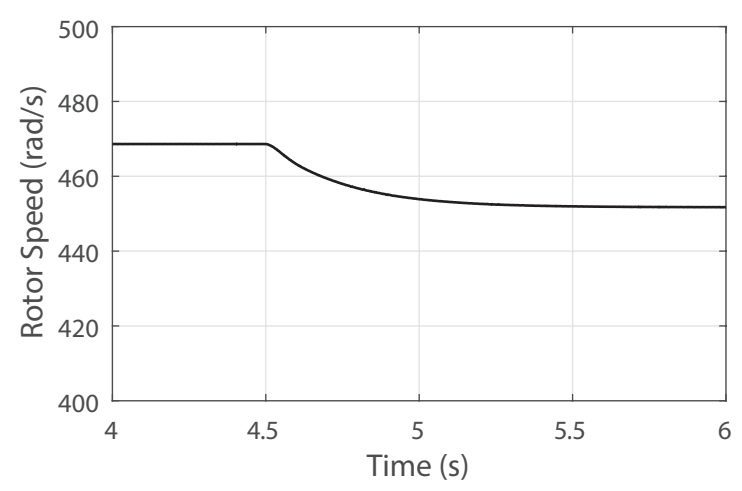

(c)

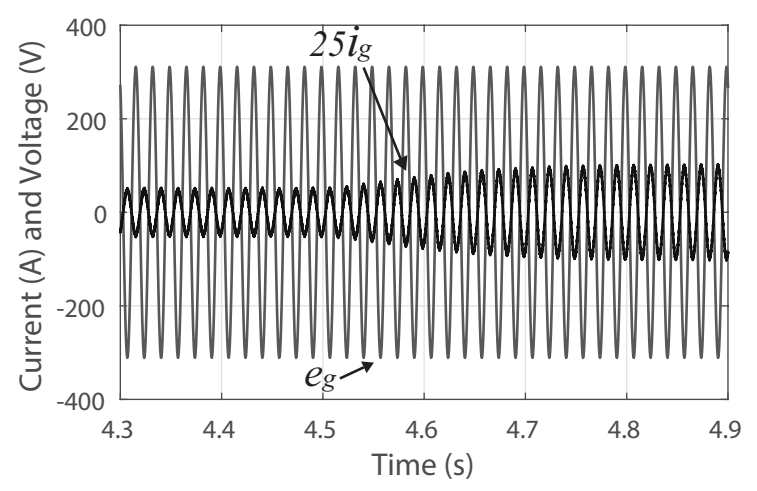

(d)

Fig. 12. Simulation results - transient-state. (a) Stator active and reactive powers $(P s$ and $Q s)$. (b) DC-link voltage $\left(v_{C}\right)$. (c) rotor speed $\left(\omega_{r}\right)$. (d) Current and voltage of the grid $\left(i_{g}\right.$ and $\left.e_{g}\right)$.
TABLE II

Setup Parameters

\begin{tabular}{cc}
\hline Parameter & Value \\
\hline Inductance of inductor filter $l_{a}$ & $12 \mathrm{mH}$ \\
\hline Resistance of inductor filter $r_{a}$ & $0.55 \Omega$ \\
\hline Capacitance of the filter $C_{a}$ & $5 \mu \mathrm{F}$ \\
\hline Capacitance equivalent of the DC-link & $2200 \mu \mathrm{F}$ \\
\hline DC-link reference voltage $v_{C}$ & $400 \mathrm{~V}$ \\
\hline Grid phase voltage & $220 \mathrm{Vrms}$ \\
\hline Switching frequency & $10 \mathrm{kHz}$
\end{tabular}

\section{EXPERIMENTAL RESULTS}

The topology presented in Figure 2 has been implemented experimentally in laboratory. DFIG parameters are shown in Table I and the setup parameters are shown in Table II. The experimental setup is based on a Digital Signal Processor (DSP) TMS320F28335 with a microcomputer equipped with appropriate plug-in boards and sensors. Results were obtained by oscilloscope Agilent DSO-X 3014A 100MHZ. The input mechanical torque was provided by a squirrel-cage induction motor (SCIM) of $0.55 \mathrm{~kW}$ fed by a WEG inverter. A photo of the experimental setup is shown in Figure 13.

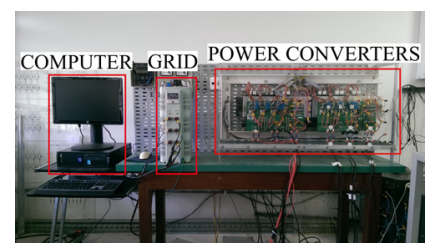

(a)

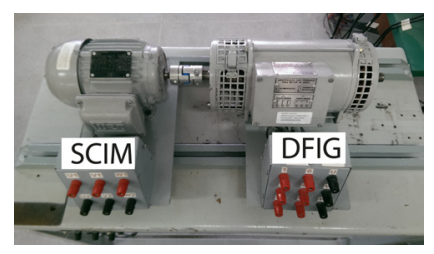

(b)

Fig. 13. Experimental setup. (a) Power converter. (b) SCIM plus DFIG.

Figures 14 and 15 illustrate steady-state experimental results, with a stator active and reactive power references of $-500 \mathrm{~W}$ and $0 \mathrm{VA}$, respectively. By measuring stator voltages and currents, Park's transformation is applied and stator active and reactive powers are calculated according to (6) and (7), respectively. Figure 14.a shows that the control system adequately adjusts both active and reactive powers to their reference values. Also, by measuring the rotor currents and applying Park's Transformation, current components $i_{r d}^{v}$ and $i_{r q}^{v}$ are the ones shown in Figure 14.b. PWM and control strategies assure balanced stator line voltages, producing balanced stator currents, as illustrated in Figures 14.c and 14.d.

Figure 15.a shows the rotor currents $i_{r 1}, i_{r 2}$ and $i_{r 3}$. They are sinusoidal and oscillate at low frequency (slip frequency). Grid current and voltage are illustrated in Figure 15.b. Note that high power factor and sinusoidal current are provided by the control system. It is possible to see the power flow from the GSC to the grid. DC-link voltage is shown in Figure 15.c, which is correctly adjusted to the value of $400 \mathrm{~V}$. 


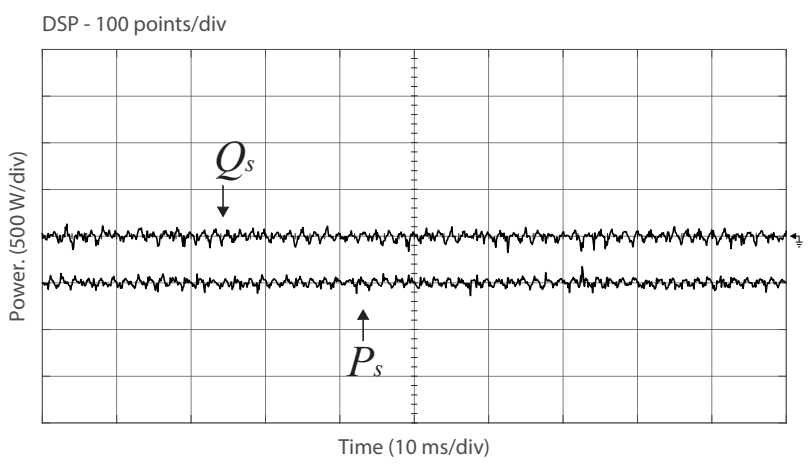

(a)

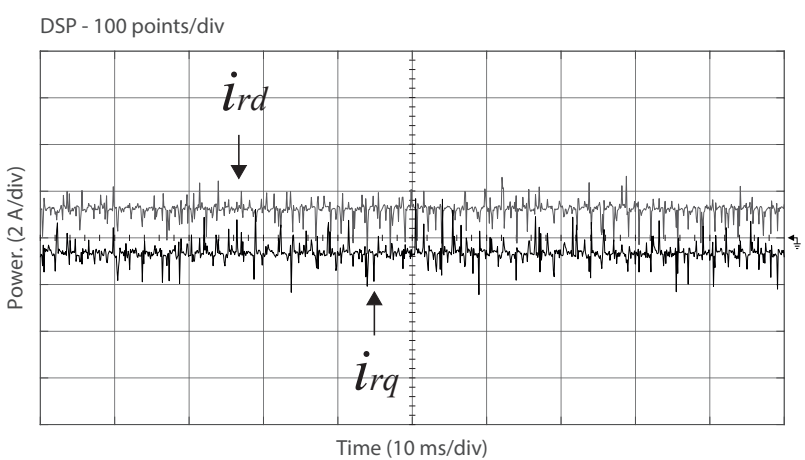

(b)

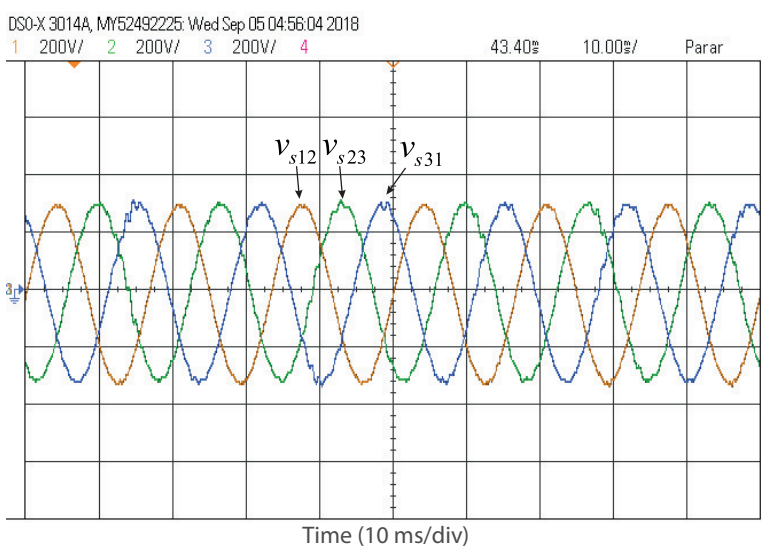

(c)

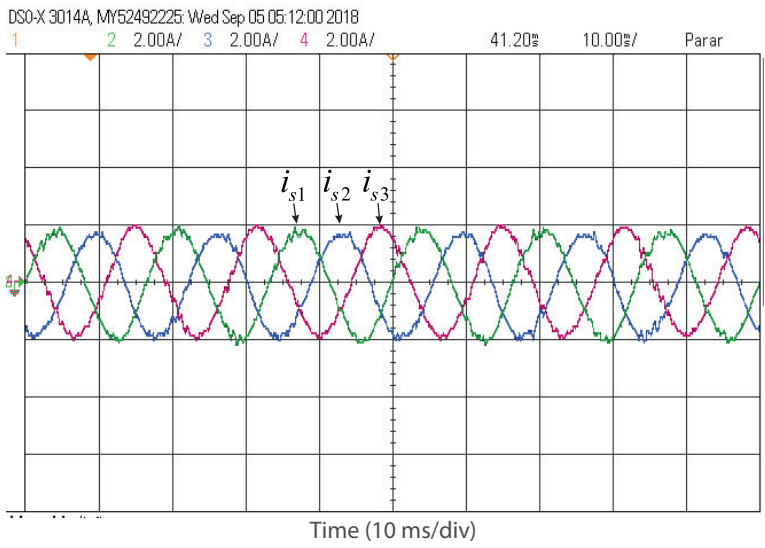

(d)

Fig. 14. Experimental results - steady-state. (a) Stator active and reactive powers $\left(P s\right.$ and $\left.Q_{s}\right)$. (b) $d-q$ rotor currents $\left(i_{r d}^{v}\right.$ and $\left.i_{r q}^{v}\right)$. (c) Stator line voltages $\left(v_{s 12}, v_{s 23}\right.$ and $\left.v_{s 31}\right)$. (d) Stator currents $\left(i_{s 1}, i_{s 2}\right.$ and $\left.i_{s 3}\right)$.
DSO-X 3014A, MY52492225: Wed Sep 05 05:17:25 2018

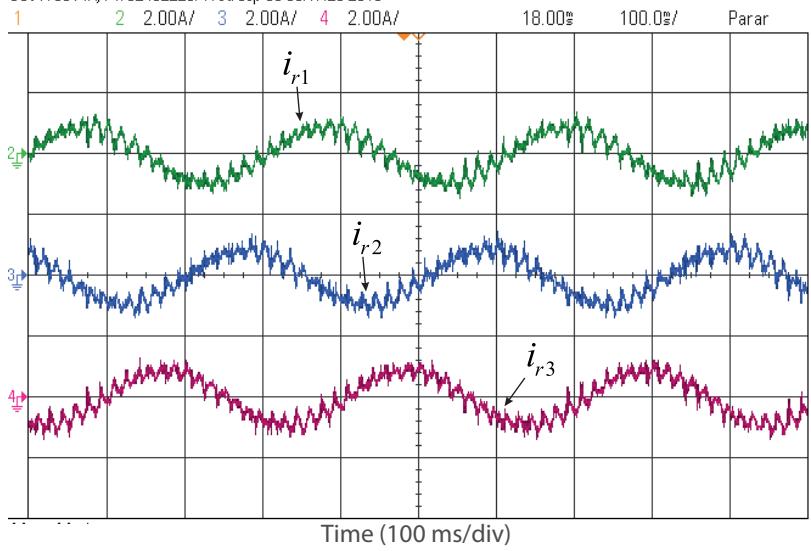

(a)

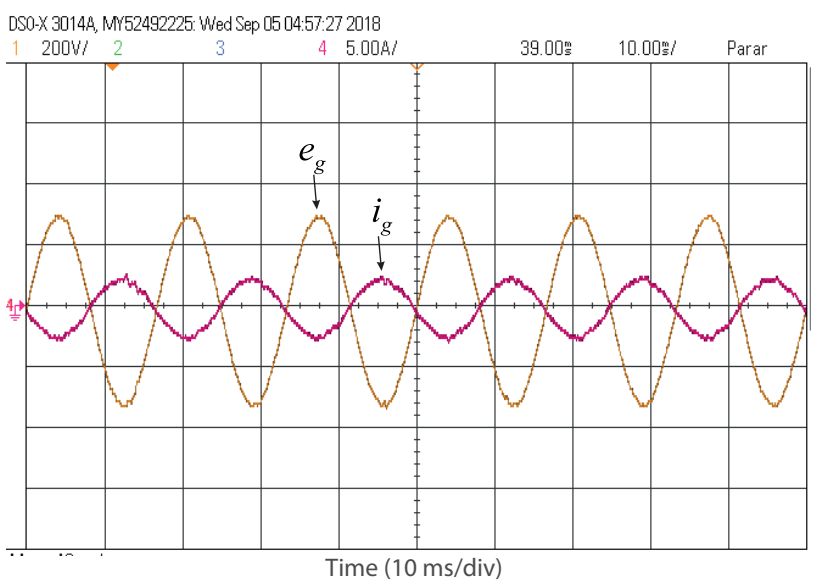

(b)

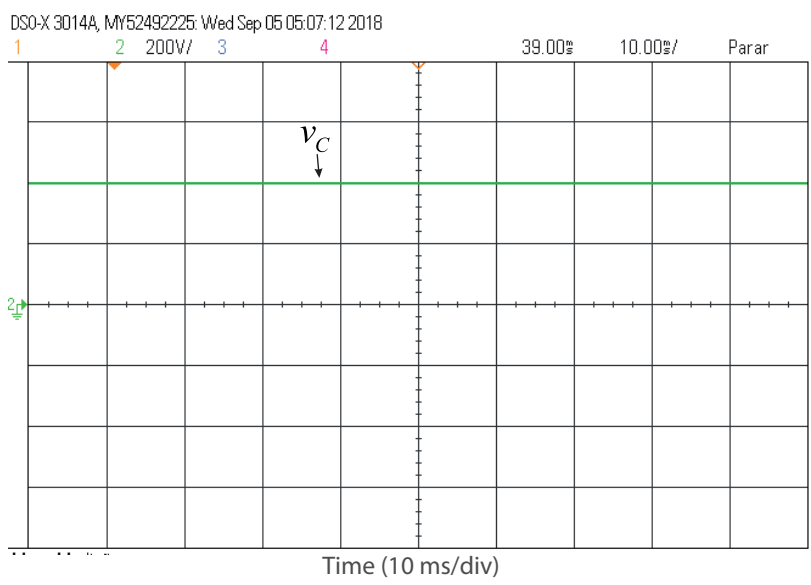

(c)

Fig. 15. Experimental results - steady-state. (a) Rotor currents $\left(i_{r 1}\right.$, $i_{r 2}$ and $\left.i_{r 3}\right)$. (b) Current and voltage of the grid $\left(i_{g}\right.$ and $\left.e_{g}\right)$. (c) DClink voltage $\left(v_{c}\right)$.

\section{CONCLUSION}

This paper presented a three-phase to single-phase to wind energy conversion system based on Doubly-Fed Induction Generator. The generator is directly connected to the single-phase source and the system has the advantages of reduced cost of the power converter (because the converter process only part of the overall output power). In the supersynchronous mode with rotor speed 1.3 times the 
synchronous speed, which is the worst case scenario, the processed power by SSC and GSC was approximately $60 \%$ and $80 \%$, respectively. In all analyzed cases, the power processed by the converters is less than the generator rated power, implying in the use of lower rated and cheaper devices. Control and PWM strategies assured balanced stator threephase voltages. Simulation and experimental results showed their validity and the feasibility of the conversion system.

\section{REFERENCES}

[1] N. Swami Naidu, B. Singh, "Doubly Fed Induction Generator for Wind Energy Conversion Systems With Integrated Active Filter Capabilities", IEEE Trans Ind Informatics, vol. 11, no. 4, p. 923-933, Aug 2015.

[2] X. Liang, "Emerging power quality challenges due to integration of renewable energy sources", in 2016 IEEE Industry Applications Society Annual Meeting, p. 1-9, Oct 2016.

[3] D. Zhou, G. Zhang, F. Blaabjerg, “Optimal Selection of Power Converter in DFIG Wind Turbine With Enhanced System-Level Reliability", IEEE Transactions on Industry Applications, vol. 54, no. 4, p. 3637-3644, July 2018, doi: 10.1109/TIA.2018.2822239.

[4] A. S. Bubshait, A. Mortezaei, M. G. Simoes, T. D. C. Busarello, "Power Quality Enhancement for a Grid Connected Wind Turbine Energy System", IEEE Transactions on Industry Applications, vol. 53, no. 3, p. 2495-2505, May 2017.

[5] R. Machado, J. Pomilio, E. Goncalves Marra, "Electronically controlled bi-directional connection of induction generator with a single-phase grid", in Industrial Electronics Society, 2001. . The 27th Annual Conference of the IEEE, vol. 3, p. 1982-1987 vol.3, Nov 2001.

[6] T. Chan, L. Lai, "Phase balancing for an induction generator operating on a single-phase power system", in Power Engineering Society Winter Meeting, vol. 1, p. 165-170 vol.1, Jan 2000.

[7] E. Marra, J. Pomilio, "Induction-generator-based system providing regulated voltage with constant frequency", IEEE Trans Ind Electron, vol. 47, no. 4, p. 908-914, Aug 2000.

[8] C. Xia, Z. Wang, T. Shi, Z. Song, "A Novel Cascaded Boost Chopper for the Wind Energy Conversion System Based on the Permanent Magnet Synchronous Generator", IEEE Trans Energy Conversion, vol. 28, no. 3, p. 512-522, Sept 2013.

[9] H. Nian, R. Zeng, J. Liu, W. Zhang, "Complementary half controlled converter for directly-driven PM synchronous generator in wind power generation application", in Energy Conversion Congress and Exposition (ECCE), p. 358-362, Sept 2009.

[10] E. dos Santos, C. Jacobina, M. Correa, N. Rocha, "Distributed generation system based on singlephase grid, induction generator and solar photovoltaic panel", in Applied Power Electronics Conference and Exposition (APEC), p. 1290-1295, Feb 2008.
[11] N. Rocha, E. de Menezes, I. de Oliveira, C. Jacobina, "Single-phase to three-phase induction generation system with two parallel single-phase half-bridge converters", in Power Electronics Conference (COBEP), p. 678-685, Oct 2013.

[12] Z. Zhang, Y. Zhao, W. Qiao, L. Qu, "A DiscreteTime Direct Torque Control for Direct-Drive PMSGBased Wind Energy Conversion Systems", IEEE Transactions on Industry Applications, vol. 51, no. 4, p. 3504-3514, July 2015.

[13] M. Ashourianjozdani, L. A. C. Lopes, P. Pillay, "Power Electronic Converter Based PMSG Emulator: A Testbed for Renewable Energy Experiments", IEEE Transactions on Industry Applications, vol. 54, no. 4, p. 3626-3636, July 2018.

[14] J. Dias, J. Diniz N, A. Almeida, E. dos Santos Junior, N. Rocha, "Low cost single-phase grid-tie generator", in Industry Applications Society Annual Meeting (IAS), p. 1-6, Oct 2013.

[15] Y. Han, J. Ha, "Wound Rotor Machine Fed by a Single-Phase Grid and Controlled by an Isolated Inverter", IEEE Transactions on Power Electronics, vol. 29, no. 9, p. 4843-4854, Sep. 2014, doi: 10.1109/TPEL.2013.2283738.

[16] K. Lee, Y. Han, J. Ha, "Wound Rotor Machine With Single-Phase Stator and Three-Phase Rotor Windings Controlled by Isolated Three-Phase Inverter", IEEE Transactions on Energy Conversion, vol. 30, no. 2, p. 558-568, June 2015, doi:10.1109/TEC.2015.2394807.

[17] G. C. Leandro, E. L. Soares, N. Rocha, "Singlephase to three-phase reduced-switch-count converters applied to wind energy conversion systems using doubly-fed induction generator", in 2017 Brazilian Power Electronics Conference (COBEP), p. 1-6, Nov 2017.

[18] N. Rocha, I. A. C. de Oliveira, E. R. C. da Silva, C. B. Jacobina, "Single-phase to three-phase generation system based on doubly-fed induction generator", in 2017 IEEE Energy Conversion Congress and Exposition (ECCE), p. 3274-3280, Oct 2017.

[19] R. Pena, J. Clare, G. Asher, "Doubly fed induction generator using back-to-back PWM converters and its application to variable-speed wind-energy generation", Electric Power Applications, IEE Proceedings -, vol. 143, no. 3, p. 231-241, May 1996.

[20] S. M. Shahruz, "Novel phase-locked loops with enhanced locking capabilities", in American Control Conference, p. 4086-4091, May 2002.

[21] C. B. Jacobina, M. B. de R. Correa, R. F. Pinheiro, E. R. C. da Silva, A. M. N. Lima, "Modeling and Control of Unbalanced Three-phase Systems Containing PWM Converters", IEEE Trans Ind Appl, vol. 37, no. 6, p. 1807-1816, Nov./Dec. 2001.

[22] Lie $\mathrm{Xu}, \mathrm{P}$. Cartwright, "Direct active and reactive power control of DFIG for wind energy generation", IEEE Transactions on Energy Conversion, vol. 21, no. 3, p. 750-758, Sep. 2006, doi: 10.1109/TEC.2006.875472. 
[23] A. R. Kumhar, "Vector Control Strategy to Control Active and Reactive Power of Doubly Fed Induction Generator Based Wind Energy Conversion System", in 2018 2nd International Conference on Trends in Electronics and Informatics (ICOEI), p. 1-9, May 2018, doi:10.1109/ICOEI.2018.8553761.

[24] V. Blasko, "Analysis of a Hybrid PWM Based on Modified Space-Vector and Triangle-Comparison Methods", IEEE Trans Ind Appl, vol. 33, no. 3, p. 756764, May/June 1996.

[25] H. W. van der Broeck, H. C. Skudelny, G. V. Stanke, "Analysis and Realization of a Pulsewidth Modulator Based on Voltage Space Vectors", IEEE Trans on Ind Appl, vol. 24, no. 2, p. 142-150, Jan./Feb. 1988.

[26] J. Holtz, "Pulsewidth modulation for electronic power conversion", Proceedings of the IEEE, vol. 82, no. 8, p. 1194-1214, Aug. 1994.

[27] A. M. Hava, U. Ayhan, V. V. Aban, "A DC bus capacitor design method for various inverter applications", in 2012 IEEE Energy Conversion Congress and Exposition (ECCE), p. 4592-4599, Sep. 2012, doi:10.1109/ECCE.2012.6342196.

\section{BIOGRAPHIES}

Filipe Vieira Rocha, was born in Ribeirão Preto, São Paulo, Brazil, in 1993. He received the B.S. degree in electrical engineering from the Federal University of Campina Grande, Campina Grande, Brazil, in 2017. Since 2017, he is working in M.S. degreeing electrical engineering in Federal University of Paraíba, João Pessoa, Brazil. His research interests include power electronics, electrical drives and renewable energy source.

Nady Rocha, was born in São Gabriel, Bahia, Brazil, in 1982. He received the B.S., M.S., and Ph.D. degrees in electrical engineering from the Federal University of Campina Grande, Campina Grande, Brazil, in 2006, 2008, and 2010, respectively. Since 2011, he has been with the Department of Electrical Engineering, Federal University of Paraíba, João Pessoa, where he is currently an Associate Professor of Electrical Engineering. His research interests include power electronics, renewable energy sources and electrical drives.

Victor Felipe Moura Bezerra Melo, was born in Pesqueira, Brazil, in 1988. He received the B.S., M.S. and Ph.D. degrees in electrical engineering from the Federal University of Campina Grande, Campina Grande, Brazil, in 2012, 2013, and 2017, respectively. From October 2014 to June 2018 he was with Federal Institute of Technology of Pernambuco (IFPE), Afogados da Ingazeira, Brazil, where he was a Professor. Since June 2018 he has been with Federal University of Paraíba, where he is currently a Professor. His current research interests include power electronics, static converters, electrical drives, and active power filters.

Edison Roberto Cabral received the B.S.E.E. degree from the Polytechnic School of Pernambuco, Recife, Brazil, in 1965, the M.S.E.E. degree from the University of Rio de Janeiro, Rio de Janeiro, Brazil, in 1968, and the Dr.Eng. degree from the Universite Paul Sabatier, Toulouse, France, in 1972. From 1967 to 2002, he was with the Department of Electrical Engineering, Federal University of Paraíba, João Pessoa, Brazil, where he was a National Senior Visiting Professor till the beginning of 2018. In 1990, he was with the Federal University of Rio de Janeiro, Rio de Janeiro, and from 1990 to 1991, he was with the University of Wisconsin Madison, Madison, WI, USA, as a Visiting Professor. From 2002 to 2012, he was with the Department of Electrical Engineering, Federal University of Campina Grande, Campina Grande, Brazil, where he is currently a Professor Emeritus, still acting. He was the Director of the Research Laboratory on Industrial Electronics and Machine Drives for 30 years. His current research interests include power electronics and motor drives. Dr. da Silva was the General Chairman of the 1984 Joint Brazilian and LatinAmerican Conference on Automatic Control, sponsored by the Brazilian Automatic Control Society (SBA), the IEEE Power Electronics Specialists Conference in 2005, and the Brazilian Conference on Automatic Control in 2012 and 2018. He is a Past-President of the SBA.

Cursino Brandão Jacobina, was born in Correntes, Brazil, in 1955. He received the B.S. degree in electrical engineering from the Federal University of Paraíba, Campina Grande, Brazil, in 1978, and the Diplôme d?Etudes Approfondies and the Ph.D. degrees in electrical engineering from the Institut National Polytechnique de Toulouse, Toulouse, France, in 1980 and 1983, respectively. From 1978 to March 2002, he was with the Department of Electrical Engineering, Federal University of Paraíba, João Pessoa, Brazil. Since April 2002, he has been with the Department of Electrical Engineering, Federal University of Campina Grande, Campina Grande, Brazil, where he is currently a Professor of Electrical Engineering. His research interests include electrical drives, power electronics and energy systems 